\title{
Euskal landa-arkitekturako eredu tradizionalaren eraikuntza-bilakaeraren eragina portaera higrotermiko pasiboan: Lea ibarreko kasu-azterketa
}

\author{
(Influence of the construction evolution
}

of the traditional Basque architectural model on its passive hygrothermal behaviour: case study of Lea Valley)

\author{
Matxalen Etxebarria Mallea ${ }^{1 *}$, Lauren Etxepare Igiñiz ${ }^{2}$, \\ Margarita de Luxán García de Diego ${ }^{3}$ \\ ${ }^{1}$ Doktoregoko ikaslea UPV/EHUko Arkitektura Sailean \\ ${ }^{2}$ Irakaslea UPV/EHUko Arkitektura Sailean \\ ${ }^{3}$ Madrileko Unibertsitate Politeknikoko (UPM) Irakasle Emeritua \\ * matxalen.etxebarria@ehu.eus
}

DOI: $10.1387 /$ ekaia.19671

Laburpena: Energia-oreka eta -eraginkortasun handiko estrategia pasiboak ditu ezaugarri arkitektura tradizionalak. Izan ere, tokiko ingurumen-baldintzen eta eraikinaren eraikuntza-ezaugarrien arteko interakzioa gertatzen da beraren barnean, eta bi aldagai horien erlazioaren menpe dago barneko giroa. Euskal etxe-eredu tradizionalaren barneko portaera higrotermiko pasiboari aldian-aldian eginiko eraikuntza-egokitzapenek eragindako eboluzioa eta bilakaera aztertzen ditu artikulu honek. Horiek jorratzeko, Lea ibarreko arkitektura tradizionala hautatu da ikerketa-eremutzat. Bizkaiko ekialdeko ibar bat da, klima epel eta hezekoa. Hango baserrien eraikuntza-ezaugarriak, xv. mendean arkitektura-eredu gisa sortuz geroztik, behin eta berriz izan dira eraldatuak, gizarte-bilakaerak eta bestelako eskakizunak tarteko; eraldaketa horiek, bestalde, eraikinon portaera higrotermiko pasiboaren eboluzioa ere ekarri izan dute. Landa-azterketaren ondorioz, lehenik eta behin, lekuko arkitektura tradizionalaren eraikuntza-sistemaren eboluzioaren azterketa egin da eredu adierazgarrienak zehazte aldera; ondoren, eredu horietako Tenperatura Operatiboaren $\left[{ }^{\circ} \mathrm{C}\right]$ eta Hezetasun Erlatiboaren [\%] datuak biltzeko, simulazio energetikoa egin da Design Builder v.5.0.1.024 softwarea baliatuz. Azkenik, eskuraturiko datuok kronologikoki alderatu dira, neguko, udako eta tarteko 
Matxalen Etxebarria Mallea, Lauren Etxepare Igiñiz, Margarita de Luxán García de Diego

urte-sasoietako eguneko balioen arabera, eta hortik eskuratu eraikuntzaren eboluzioak zer-nolako eragina izan ote duen barneko portaera higrotermikoan.

Hitz gakoak: arkitektura tradizionala, eraikuntza-eboluzioa, portaera higrotermikoa.

\begin{abstract}
Traditional architecture presents energy balance and high-efficiency passive strategies as a function of the outdoor environmental conditions and the characteristics of the construction of the building. Therefore, the indoor environment depends on the relationship between the both of them. The main objective of this article is to diagnose and determine the evolution of the indoor passive hygrothermal behaviour of the traditional Basque architectural model as a consequence of its historically successive constructive adaptation. For that purpose, the traditional architecture of Lea River valley, which is located in the Historical Territory of Bizkaia and characterized by a temperate-humid climate, has been analysed. Since its origin in the $15^{\text {th }}$ century as an «architectural model», it has suffered from many constructive adaptive solutions due to the social, economic and technical demands, which have also implied the evolution or variation of its passive hygrothermal behaviour. The in-situ constructive data collection has led to define the most representative models in order to obtain the base behaviour diagnosis. The two hygrothermal variables, that is, the Operative Temperature $\left[{ }^{\circ} \mathrm{C}\right]$ and Relative Humidity [\%], have been obtained from computational models that have been defined by the energy simulation Design Builder v. 5.0.1.024 programme. The obtained data has been collected according to the external environmental conditions and the building type. Finally, the results have been summarized and chronologically compared based on daily basis of winter, summer and mid-season division.
\end{abstract}

Keywords: traditional architecture, constructive evolution, hygrothermal behaviour.

\title{
1. SARRERA
}

Energia-oreka eta -eraginkortasun handiko estrategia pasiboak ditu ezaugarri arkitektura tradizionalak. Izan ere, tokiko ingurumen-baldintzen eta eraikinaren eraikuntza-ezaugarrien arteko interakzioa gertatzen da beraren barnean. Barneko giroaren kalitate higrotermikorik egokiena lortzeko eredu unibertsalik ezean, tokian tokiko eredu propio eta berezkoak garatu eta eraiki izan dira eremu klimatiko bakoitzean [1-4]. Beraz, esan daiteke arkitektura tradizionala arkitektura bioklimatikoaren aitzindaria dela, bai eta tokian tokiko baliabide, material eta tekniken garapenaren isla ere [5-6]. Artikulu honek euskal landa-arkitektura tradizionala hartzen du ikerketaeremutzat, eta itxitura-elementuen eraikuntza-bilakaerak beraren barne-giroari nola eragiten dion jakitea du helburu, beraren barneko gorabehera higrotermiko pasiboaren irakurketa dela medio. Lagungarri izan nahi du, halaber, berariazko eraikuntza ezaugarriak kanpoko ingurumen-baldintzetara zenbateraino egokitu diren ezagutzeko [7-10], baita biziberritzeko eta esku-hartzeko lanetan jatorrizko eraikina zer neurritan errespetatu edo egokitu daitekeen jakiteko ere. 
Aldaerak aldaera, euskal landa-arkitekturako eredu tradizionalak baditu berezko ezaugarri batzuk, han eta hemen ezagutu daitezkeenak. Eraikin handiak dira, beren barnean hainbat abeltzaintza, nekazaritza-jarduera eta aldi bereko funtzio hartzeko gai direnak: korta, lastategia, garautegia eta dolarea, adibidez, baina baita, funtzio horien ondoan eta gainerako erabileretatik bereizita, etxebizitza ere. Haren ezaugarriak lurraldearekin, eskualdearekin, arkitektura-aldiarekin, nekazaritza-ekoizpeneko sistemarekin, eraikuntza-teknikekin edota etxejabeen egoera ekonomikoarekin zeuden zuzenki lotuak. Nolanahi ere, nahiz eta tokian tokiko eta aldian aldiko aldaerak izan, esan daiteke ezaugarri morfologiko nagusiei eutsi dien eraikin mota tradizional bat dela. Ezaugarri morfologiko komuntzat jo ditzagun bolumena, tamaina handia, itxura konpaktua eta askea, maldadun teilatua, azalera laukizuzena hartzen duen bizpahiru solairutan banatutako barne-antolamendua eta arestian aipaturiko funtzioak.

Eredu arkitektoniko tradizional honek mendetan iraun du euskal lurralde osoan. Alabaina, lan honek, lurralde osoa eta aldaera guztiak aztertzea baztertu, eta Lea ibarreko eremu geografikoko ereduak hartu ditu aintzat.

\section{METODOLOGIA}

Lan honen lehenengo urratsa ikergai diren landa-arkitekturen ingurumen-baldintzak (hau da, kokapena eta ezaugarri klimatikoak) aztertzea izan $\mathrm{da}$, horien eta etxeen barneko egoera higrotermiko pasiboaren arteko erlazioa ezartzeko bidea zabaltzeko.

Hurrenik, landa-lanean eta erreferentzia bibliografikoetan oinarrituta [11-15], landa-arkitektura tradizional honen ereduaren azterketa sakona egin da, berariazko eraikuntza-bilakaera eta ondoriozko ezaugarri teknikoak zehazteko: eraikuntza-sistema, egitura, konposizio arkitektonikoa eta ezaugarri materialak. Hala, erreferentzia-eredu adierazgarrienak aukeratu, eta haien portaera higrotermiko pasiboaren irakurketa egin da Design Builder v.5.0.1.024 simulazio energetikorako softwarea baliatuz.

Azkenik, simulatutako ikerketa-eredu bakoitzetik lortutako aldagai higrotermiko bien (hau da, Tenperatura Operatiboaren $\left[{ }^{\circ} \mathrm{C}\right]$ eta Hezetasun Erlatiboaren [\%]) datuak bildu dira; kronologikoki bildu ere, eraikuntza-bilakaeraren ondorioz izandako aldaketa zenbatesteko. Horrela, beraz, neguko, udako eta tarteko urte-sasoietako egunetako balioak eskuratuta, oinarrizko portaera zehaztea lortu da. 
Matxalen Etxebarria Mallea, Lauren Etxepare Igiñiz,

Margarita de Luxán García de Diego

\section{INGURUMENA ETA EZAUGARRI KLIMATIKOAK}

Lea ibarreko ingurune fisikoaren ardatza ibaiaren ibilgua bera da, $24 \mathrm{~km}$ eskasetan Oiz mendiko iparraldeko magalean jaio eta Lekeition itsasoratzen dena. Goi-mendi, mendixka, tontor eta kota baxuko lur-eremuen arteko desberdintasunek haran estu, latz eta V itxurakoa osatzen dute. Horrez gain, klimari dagokionez, itsasoarekiko gertutasuna tarteko, eta indarrean dagoen Eraikuntzaren Kode Teknikoaren [16] araberako erreferentzia klimatikoak kontuan hartuta, ibarra bitan banatzen da: itsasotik gertu eta 250 m-ko altitudearen azpiko eremuei $\mathrm{C} 1$ egokitzen zaie, eta mendi inguruetan, edo $250 \mathrm{~m}$-tik gora daudenei, aldiz, D1. Alabaina, simulazio-softwarea tarteko, programak aurrez ezarrita dakartzan Bilbao-SWEC eta San Sebastian-SWEC datu klimatikoek [17] tokiko klimarekiko antzekotasun handiagoak aurkezten dituztenez, bi horiek baliatu dira C1 eta D1 erreferentzien partez, hurrenez hurren (1. taula).

1. taula. Bilbori eta Donostiari dagozkien hilekako datu klimatikoak. Espainiako Meteorologia Agentzia Nazionala [18]. Datu-base hau oinarri hartuta Energy Pluserako baliagarri diren SWEC [17] artxibo klimatikoak sortu dira Climed [19] softwarea erabiliz.

\begin{tabular}{|c|c|c|c|c|c|c|c|c|c|c|c|c|}
\hline Bilbo & \multirow{2}{*}{ Urt } & \multirow{2}{*}{ Ots } & \multirow{2}{*}{ Mar } & \multirow{2}{*}{ Apr } & \multirow{2}{*}{ Mai } & \multirow{2}{*}{ Eka } & \multirow{2}{*}{ Uzt } & \multirow{2}{*}{ Abu } & \multirow{2}{*}{ Ira } & \multirow{2}{*}{ Urr } & \multirow{2}{*}{ Aza } & \multirow{2}{*}{ Abe } \\
\hline (1981-2010) & & & & & & & & & & & & \\
\hline Bb. $\mathrm{T}^{\mathrm{a}} \max .\left({ }^{\circ} \mathrm{C}\right)$ & 13,4 & 14,3 & 16,5 & 17,6 & 20,8 & 23,4 & 25,4 & 26,0 & 24,6 & 19,4 & 15,4 & 11,9 \\
\hline $\mathrm{Bb} . \mathrm{T}^{\mathrm{a}} \min \left({ }^{\circ} \mathrm{C}\right)$ & 5,1 & 5,1 & 6,4 & 7,6 & 10,6 & 13,4 & 15,4 & 15,7 & 13,8 & 11,4 & 8,1 & 5,9 \\
\hline $\mathrm{Bb} \cdot \mathrm{T}^{\mathrm{a}}\left({ }^{\circ} \mathrm{C}\right)$ & 9,3 & 9,7 & 11,5 & 12,6 & 15,7 & 18,4 & 20,4 & 20,9 & 19,2 & 16,4 & 12,4 & 9,9 \\
\hline Gorabehera term. $\left({ }^{\circ} \mathrm{C}\right)$ & 8,3 & 9,2 & 10,1 & 10,0 & 10,2 & 10,0 & 10,0 & 10,3 & 10,8 & 8,0 & 7,3 & 6,0 \\
\hline Bb. Prezip. $(\mathrm{mm})$ & 120 & 86 & 90 & 107 & 78 & 60 & 50 & 76 & 73 & 111 & 147 & 122 \\
\hline $\mathrm{RH}(\%)$ & 72 & 69 & 68 & 69 & 69 & 70 & 71 & 72 & 71 & 71 & 73 & 72 \\
\hline Donostia & \multirow{2}{*}{ Urt } & \multirow{2}{*}{ Ots } & \multirow[b]{2}{*}{ Mar } & \multirow[b]{2}{*}{ Apr } & \multirow[b]{2}{*}{ Mai } & \multirow{2}{*}{ Eka } & \multirow[b]{2}{*}{ Uzt } & \multirow[b]{2}{*}{ Abu } & \multirow[b]{2}{*}{ Ira } & \multirow{2}{*}{ Urr } & \multirow[b]{2}{*}{ Aza } & \multirow{2}{*}{ Abe } \\
\hline$(1981-2010)$ & & & & & & & & & & & & \\
\hline Bb. $\mathrm{T}^{\mathrm{a}} \max .\left({ }^{\circ} \mathrm{C}\right)$ & 11 & 11,5 & 13,4 & 14,5 & 17,7 & 20,0 & 21,8 & 22,5 & 21,1 & 18,5 & 14,0 & 11,6 \\
\hline $\mathrm{Bb} . \mathrm{T}^{\mathrm{a}} \min \left({ }^{\circ} \mathrm{C}\right)$ & 5,9 & 5,9 & 7,2 & 8,1 & 11,1 & 13,8 & 16,0 & 16,5 & 14,8 & 12,4 & 8,7 & 6,6 \\
\hline $\mathrm{Bb} \cdot \mathrm{T}^{\mathrm{a}}\left({ }^{\circ} \mathrm{C}\right)$ & 8,5 & 8,7 & 10,3 & 11,3 & 14,4 & 16,9 & 18,9 & 19,5 & 18,0 & 15,5 & 11,3 & 9,1 \\
\hline Gorabehera term. $\left({ }^{\circ} \mathrm{C}\right)$ & 5,1 & 5,6 & 6,2 & 6,4 & 6,6 & 6,2 & 5,8 & 6,0 & 6,3 & 6,1 & 5,3 & 5,0 \\
\hline Bb.prezip. (mm) & 141 & 110 & 113 & 138 & 120 & 90 & 86 & 117 & 111 & 159 & 169 & 151 \\
\hline $\mathrm{RH}(\%)$ & 75 & 74 & 74 & 77 & 78 & 82 & 83 & 83 & 79 & 75 & 76 & 75 \\
\hline
\end{tabular}




\section{EUSKAL EREDU ARKITEKTONIKO TRADIZIONALAREN ERAIKUNTZA-BILAKAERA}

Portaera higrotermikoa eta eraikuntza-bilakaera erlazionatu ahal izateko, eboluzio-ezaugarriak identifikatu beharra dago lehenik. Horretarako landa-lana eta azterketa bibliografikoa ezinbestekoak izan dira. Arkitektura-eredu honen eraikuntza eta arkitektura hainbat autorek [11-15] aztertu dute 1920ko hamarkadaz geroztik. Halaxe deskribatzen du azken urteotako autore batek: «baserria eraikin-motatzat jotzen badugu, berariazko identitatea duen arkitektura-eredutzat» [15], jatorria, nonbait, XV. mendean dauka. Autore batzuek mende horretako hondar urteetan kokatzen dute [15]; metodo dendokronologikoan oinarrituriko azken ikerketek [20], baina, XV. mendearen erdialdean. Eboluzio-ezaugarrien sailkapen gisa, nolanahi ere, «arkitekturaren historiaren garai klasikoak» eta eraikuntzaaroak lotzen dituena hartu da oinarri: gotiko-berpizkundeko lehenengo aroa (XV. mendearen erdialdetik XVII.aren erdialdera doana, XVI. eta XVII. mende bitarteko berpizkundekoa barne), garai barroko jori eta aberatsa (XVII. mendearen erdialdetik XVIII.aren amaiera arte doana), eta, azkenik, eredu horren gainbehera ekarri zuen azken aro neoklasikoa (XIX. mendea).

Dena dela, bertatik bertara egindako azterketak eta arestian azalduriko sailkapena aintzat harturik, ondorengo taulan (2. taula) eta irudian (1. irudia) zehazten diren garaiak eta azpiereduak baino ez dira izan kontuan ikerketa-lan honetarako.

2. taula. Euskal arkitektura-eredu tradizionalaren bilakaeraren araberako sailkapena.

\begin{tabular}{l|l|l}
\hline \multicolumn{1}{c|}{ Garai klasikoa } & Mendea & \multicolumn{1}{c}{ Azpieredua } \\
\hline Gotiko-Berpizkundea & XV-XVII & 1. tipoa. Bizkaitarra \\
\hline Berpizkundea & XVI-XVII & 2. tipoa. Ataripe dintelduna, zuratua \\
\hline Barrokoa & XVII-XVIII & $\begin{array}{l}\text { 3.1 tipoa. Ataripe dintelduna, erdi zuratua } \\
\text { 3.2 tipoa. Hiru zentroko arkudun ataripeduna }\end{array}$ \\
\hline
\end{tabular}

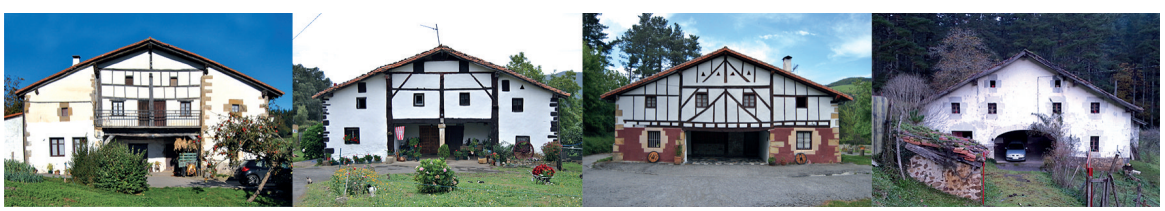

1. irudia. Gotiko-berpizkundeko 1. tipoaren (Gerrikabeitia baserria), berpizkundeko 2. tipoaren (Ormaetxea baserria), eta barrokoko 3.1 (Barrutieta baserria) eta 3.2 tipoen (Esuneta baserria) gaur eguneko egoeren irudiak. 
Matxalen Etxebarria Mallea, Lauren Etxepare Igiñiz,

Margarita de Luxán García de Diego

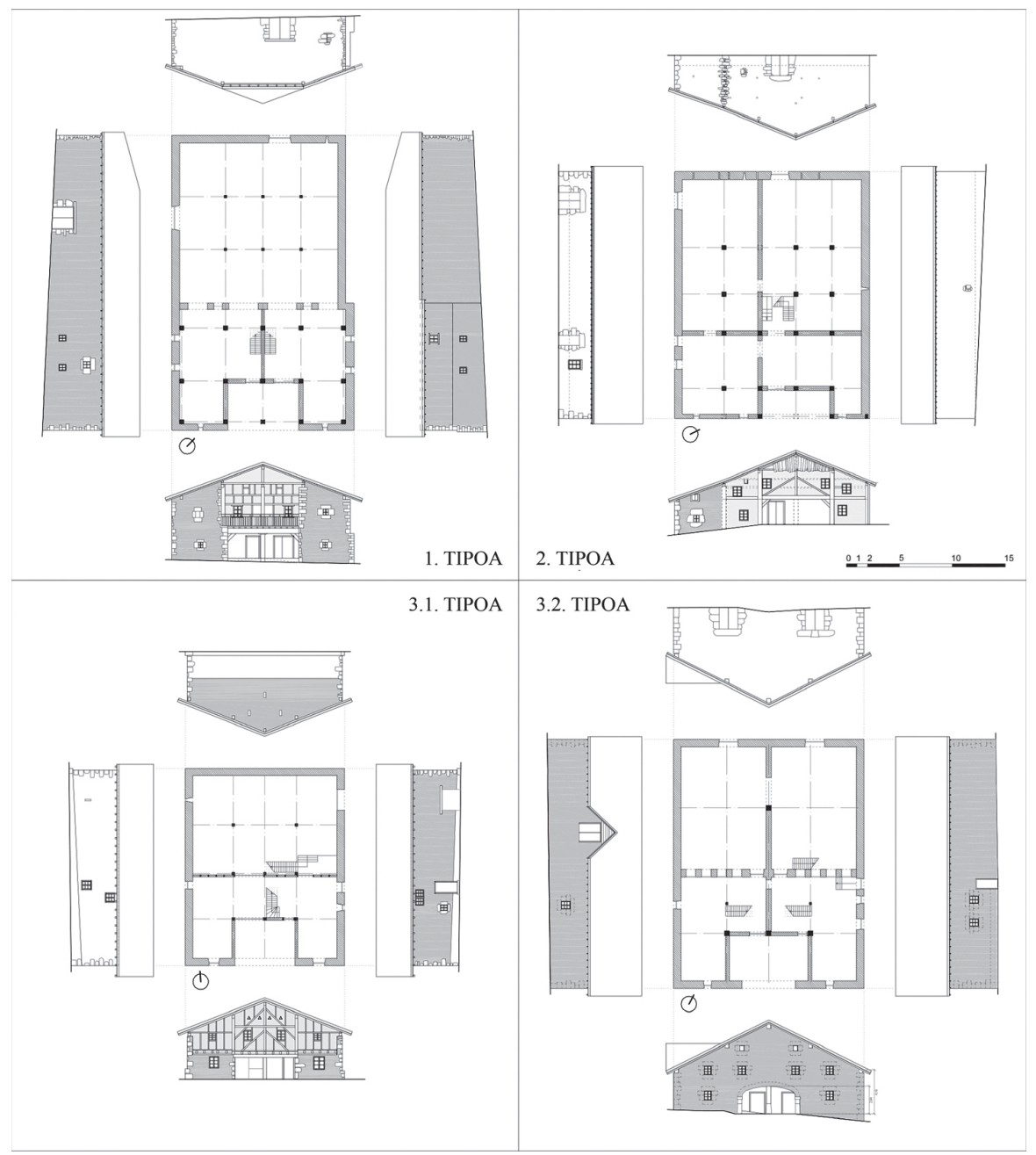

2. irudia. Gotiko-berpizkundeko 1. tipoaren (Gerrikabeitia baserria), berpizkundeko 2. tipoaren (Barrenetxea baserria), eta barrokoko 3.1 (Barrutieta baserria) eta 3.2 tipoen (Esuneta baserria) azterketa grafikoak.

\subsection{Gotiko-berpizkundeko ereduaren deskribapena. 1. tipoa}

Hiru hormartek osatzen dute aurrealdeko fatxada nagusia. Hormarte edo habearte horiek, bestalde, material-konposizio ezberdina ageri dute; ertzetakoak hareharriz daude eraikita, eta erdikoak, berriz, zurajea edo habeteria ageri du. Habeteria horrek, fatxadaren euskarri diren zutabe eta habeez eraikia denak, bilbe erregular bat osatzen du, eta bilbe ho- 
rretan bertan txertatzen dira leihoak. Halaber, erdiko hormarte hori, zurezko egitura nagusiaren plano berean dagoenez, albokoetatik atzeratuta ageri da. Gainerako fatxada eta hormak hareharrizko harlangaitzez eraikiak dira.

Etxeko sarrerako atartea erdiko habeartean kokatzen den sekzio sendoko zurezko habetzanez osatuta dago. Barnealdean ere kanpotik ikusi eta hauteman daitekeen zurezko egitura pisutsua ageri da, haritzezko habe eta zutabe pieza bakarrekoek osatua. Barne-egitura horrek ez du inguruko harrizko horma sendoekin loturarik, eta bere gain hartzen ditu zama guztiak. Ondorioz, perimetroko harrizko horma sendoak teilatuaren zamarako euskarria eta itxitura-azala baino ez dira.

Eraikinaren barne-banaketan, nekazaritza-abeltzaintzarako gunea eta etxebizitzarako gunea solairuz solairu horizontalki banatzen dituen zeharkako harrizko horma ageri du, zeina bizkaitar ereduaren ezaugarri nagusietakoa baita.

\subsection{Berpizkundeko ereduaren deskribapena. 2. tipoa}

Eraikuntza-teknika eta -material xumeagoekin egina bada ere, jatorrizko bizkaitar ereduaren bilakaera tipologikoa da. Egokitzapen-prozesuaren ondorioz, erdiko hormartearen atzerapena desagertu, eta itxitura, zurezko egituraren kanpoaldetik kokatu beharrean, zutabe eta habeen artean kokatzen da.

Materialen konposizioari dagokionez, behe-oina eta goikoak horizontalki bereizita ageri dira aurrealdeko fatxadan. Hartara, behe-oineko itxitura-atala hareharrizko harlangaitz-hormaz egina dago, eta goiko solairuak, aldiz, zurezko bilbaduraz. Bilbearen zurezko piezen artean, itxitura-azalaren betegarri gisa, igeltsu-morteroz babestutako hareharrizko pieza txiki eta arinagoak baliatzen dira.

Eredu honek ere barneko zeharkako banaketa-horma sendoa dauka.

\subsection{Eredu barrokoaren deskribapena}

Aldi barrokoari dagozkion baserriak dira azterturikoen artean aberatsenak, konposizioaren ikuspegitik ez ezik, baliaturiko materialengatik ere. Oparotasun horren ondorioz, hainbat azpieredutan sailkatu badaitezke ere, elkarren artean desberdinenak diren bietan oinarritu da ikerketa-lan honen garapena: 
Matxalen Etxebarria Mallea, Lauren Etxepare Igiñiz,

Margarita de Luxán García de Diego

\section{1 tipoa}

Berpizkundeko ereduan bezala, fatxada nagusia bitan banatzen da horizontalki. Behe-oina hareharriz edo kareharriz altxatutako harlangaitzhorma sendoa da, eta horren gainean, horman bertan bermatua, zurezko bilbaduraz osatutako azala ageri da. Berpizkundeko bilbadurarekin alderatuz, ordea, eredu honen bilbadurak diseinu konplexuagoa du (txarrantxa makurrak dauzka, esaterako). Halaber, langen eta muntagen arteko tarteak ixteko, harrizko pieza arinak ez ezik, adreilu zeramikoak ere baliatzen ditu.

Aurreko ereduetan bezala, gainerako fatxadak hareharrizko harlangaitzez daude eraikiak, baina, barne-banaketari dagokionez, zeharkako mehelinaren eraikuntza aldatu, eta harri-horma sendoa izatetik zurezko bilbaduraz osatutako horma arinagoa izatera pasatu da, fatxada nagusiaren antzeko itxura hartuz.

\section{2 tipoa}

Barroko garaiko ereduen artean, materialen, eraikuntzaren eta egituraren ikuspegitik garapen handiena bizi izandako azpieredua da. Aurrealdeko atartea erabat aldatu eta garaiko tekniketara egokitua izan da; hau da, harlanduz osatutako arkuduna izatera pasatu da; puntu erdikoa edota arku beheratua zaharrenetan, eta hiru zentrokoa aldi bereko garatuenetan.

Beraren egitura itxitura-hormek eta barne-banaketako horma sendoek osatzen dute nagusiki, kareharrizko harlangaitzez eraikitakoak denak. Horma horiekin batera, haritzezko habe-zutabezko egitura bat ere ageri da, baina, haien sekzioa eta luzera (zutabeen kasuan solairutik solairura doana) txikiagoak izateaz gain, kopurua ere murritzagoa da aurreko garaietako ereduekin alderatuz gero.

Sarrerako arkua osatzeko erabilitako harlanduen teknika eta konposizioari jarraikiz, fatxaden arteko elkarguneak, ate-ertzak eta leiho-hegiak kareharrizko harlanduz eraikiak daude, hormen gainerako harlangaitz-azalerak ez bezala.

Barroko aldian, gizartean ohikoa bilakatu zen eskaerari jarraikiz, bi familiari toki egiteko egokitu ziren barrenetik, eta, hala, zeharkako horma banatzaileaz gain, luzetarakoa ere ageri da, etxea bi bizitokitan banatzen duena. 1. irudiak adierazi bezala, bi familia aterpetzeko premia berriak aurretik eraikiriko etxeei ere eragin zien [21], halako moduz non gaur egun bi zatitan banatuak ageri diren fatxada nagusiaren eta erdiko hormaren arteko azaleran. 


\section{IKERKETA-EREDUAK. ORDENAGAILU BIDEZKO SIMULAZIOA}

Jarraian, aztertu beharreko eredu nagusiak aukeratuta, sasoiz sasoiko eta urteko aldagai higrotermikoen datuak (hau da, Tenperatura Operatiboa $\left[{ }^{\circ} \mathrm{C}\right]$ eta Hezetasun Erlatiboa [\%]) eskuratzearren, ordenagailu bidezko simulazio energetikoko ereduak garatu dira EnergyPlus 8.5 bertsioan oinarritzen den DesignBuilder v.5.0.1.024 softwarearekin. Alabaina, lortutako aldagaien datuak alderagarriak izateko, aurretiaz zenbait oinarrizko modelizazio-irizpide ezartzea ezinbestekoa izan da.

Eraikinak aldian aldiko beharrizanen arabera egokituak izan badira ere, azterketa honetarako beren egoera originalari eutsi izan baliote bezala definitu izan dira, hau da, haien ereduaren deskribapenari jarraikiz. Hortaz, jarraian deskribatutako irizpideen araberakoa da ereduaren definizioa.

\subsection{Aldagai klimatikoak eta lekuko informazioa}

Hirugarren idazpuruan azaldu bezala, ibarra bi eremu klimatikotan banatua dago. Beraz, ikerketa eredu bakoitza bere altitudearen araberako erreferentzia klimatikoaren menpe simulatu da; hau da, Bilbao-SWEC edo San Sebastian-SWEC ereduetako baten menpe. Halaber, nahiz eta oro har hego-ekialdera begira eraikiak izan, eredu bakoitza bere orientazioaren arabera modelizatu da. Bestalde, eraikuntza-ereduaren kokapen-ezaugarri eta banakako izaeraren ondorioz, haizearekiko esposizioaren aldagaia konstantetzat jo da, eta eredu guztiak simulazio-programak eskaintzen duen haizearekiko esposizio kaskarrenaren menpe simulatu dira.

\subsection{Itxitura-azala}

Arkitektura-azpiereduon barne-antolakuntza antzekoa izanik garai guztietan, haien barneko portaera higrotermikoaren bilakaera kanpoko azal termikoaren eboluzio materialaren ondoriotzat har daiteke batik bat. Azal horren eraikuntza-sistema konplexua da inondik ere, materialen definizioari dagokionez ez ezik, baita konposizioari dagokionez ere. Izan ere, fatxadaazalera berean, portaera termiko desberdina duten itxitura-material ezberdinak ageri eta konbinatzen dira. Ondorioz, egindako landa-lanaren emaitza gisa eta gaur egungo Eraikuntzaren Kode Teknikoak ezartzen duen Eraikuntza Elementuen Katalogoaren arabera [22] definitu dira haien arkitektura-, material- eta eraikuntza-ezaugarriak (3. taula). 
Matxalen Etxebarria Mallea, Lauren Etxepare Igiñiz,

Margarita de Luxán García de Diego

3. taula. Materialen ezaugarriak. Eraikuntzaren Kode Teknikotik eskuratuak [22].

\begin{tabular}{|c|c|c|c|c|}
\hline MATERIALA & $\underset{\left[\mathrm{kg} / \mathrm{m}^{3}\right]}{\varrho}$ & $\begin{array}{c}\lambda \\
{[\mathrm{W} / \mathrm{m} . \mathrm{K}]}\end{array}$ & $\begin{array}{c}\mathrm{Cp} \\
{[\mathrm{J} / \mathrm{kg} \cdot \mathrm{K}]}\end{array}$ & $\mu$ \\
\hline \multicolumn{5}{|l|}{ HARRIAK ETA LURZORU NATURALA } \\
\hline Hareharria & $2.200 \leq \rho \leq 2.600$ & 3,00 & 1.000 & \\
\hline Kareharria & $1.800 \leq \rho \leq 1.990$ & 1,40 & 1.000 & 40 \\
\hline Lurra & $\rho \leq 2050$ & 0,52 & 1.840 & - \\
\hline \multicolumn{5}{|l|}{ ZURA } \\
\hline Pisu ertaineko hostotsua (haritza edo gaztainondoa) & $565 \leq \rho \leq 750$ & 0,18 & 1.600 & 50 \\
\hline \multicolumn{5}{|l|}{ MORTEROA } \\
\hline Zementua edo kare-morteroa & $1.800 \leq \rho \leq 2.000$ & 1,30 & 1.000 & 10 \\
\hline \multicolumn{5}{|l|}{ ZERAMIKA-LANA } \\
\hline Adreilu trinkoa & 2.300 & 0,85 & 1.000 & 10 \\
\hline Teila & 2.000 & 1,00 & 800 & 30 \\
\hline MATERIALA & $\begin{array}{c}\rho \\
{\left[\mathrm{kg} / \mathrm{m}^{3}\right]}\end{array}$ & $\begin{array}{c}\mathrm{UH}, \mathrm{V}_{\text {horizontala }} \\
{\left[\mathrm{W} / \mathrm{m}^{2} \cdot \mathrm{K}\right]}\end{array}$ & $\begin{array}{c}\mathrm{UH}, \mathrm{V}_{\text {bert }} \\
{\left[\mathrm{W} / \mathrm{m}^{2} .\right.}\end{array}$ & \\
\hline \multicolumn{5}{|l|}{ MARKOA } \\
\hline Dentsitate ertaineko zura & 500 & 2,00 & 2,10 & \\
\hline \multicolumn{5}{|l|}{ KOLOREZTATU GABEKO BEIRA } \\
\hline LODIERA [mm] & $g^{\perp}$ & UH,Vhori. & $\mathrm{UH}, \mathrm{V} b$ & \\
\hline Beira bakarra & 0,85 & 6,90 & 5,70 & \\
\hline
\end{tabular}

\subsection{Geometria}

Definizio geometrikoari dagokionez, ahal bezainbeste sinplifikatu dira. Banaketa adiabatikoak, nahiz eta inertzia termikoa, izan, baduten, ez dira aintzat hartu, haien gaitasun termikoa arbuiagarria baita itxitura-horma sendoekin alderatuz gero. Ondorioz, solairu bakoitzeko zona termikoak kanpoko itxiturek eta erdiko zeharkako mehelinek (zeharkakoa kasu guztietan, baita luzetarakoa ere beste zenbaitetan) definitzen dituzte (2. irudia). 

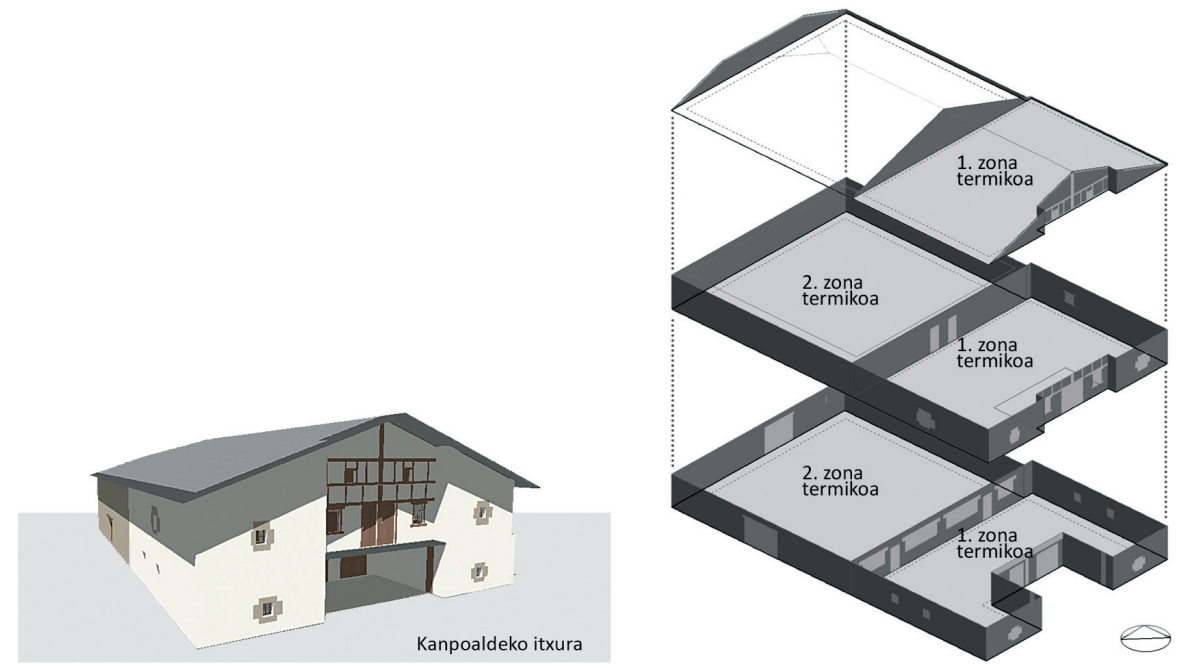

3. irudia. Design Builder simulazio-softwarea baliatuta definitutako ereduen adibideetako bat: kanpoko 3D irudia (uztailaren 15a, 12 p.m.) eta barne-banaketa termikoak solairuz solairu.

\subsection{Okupazio- eta funtzio-parametroak}

Halaber, haien portaera higrotermiko pasiboaren neurketa helburu nagusia izanik, analisi zuzena egiteko moduko balio fidagarriak eskuratzearren eta barne-karga termikoen eragina saihestearren ere, ez dira ez erabileraren ez okupazioaren aldagaiak zehaztu. Beraz, eraikinak hutsik eta funtzio zehatzik gabeak balira bezala definitu dira.

\subsection{Airearekiko iragazgaiztasuna}

Bestalde, jatorrizko funtzio-aniztasunaren ondorioz eta bao-zuloetan, leihoetan edo material ezberdinen arteko junturetan barrena gertatzen diren infiltrazioak aztertuta, aire-berritzea etengabekoa dela baiezta daiteke. Beraz, itxituraren airearekiko iragazgaiztasuna oso urria denez, simulazio-programak eskainitako infiltrazio-eredu kaskarrena hautatu da; hau da, 10ren/h 50 Pa-eko presiopean [23].

\section{EMAITZAK}

Arkitektura-ereduaren eboluzioak eraikinaren aurrealdeko fatxadari eragin dio gehien, hark jasan baititu aldaketa nagusiak. Ondorioz, solairu bakoitzeko «1 zona termikoa» hartu da portaera higrotermiko pasiboaren azterketa-gunetzat; mehelinaren eta aurrealdeko fatxadaren artean eratzen den gunea, alegia. 
Matxalen Etxebarria Mallea, Lauren Etxepare Igiñiz,

Margarita de Luxán García de Diego

Behin kasu guztien modelizazioa eta simulazio-prozesua egin eta gero, Tenperatura Operatiboaren $\left[{ }^{\circ} \mathrm{C}\right]$ eta Hezetasun Erlatiboaren [\%] balioak jaso dira, banan-banan eta konparatiboki, eraikuntza-bilakaeraren eragina zenbatetsiz. Helburu horrekin, 4. taulan ikus daitekeen bezala, tipo bakoitzeko bizpahiru ereduren solairu bakoitzeko urtaroko maximoaren, minimoaren eta batezbestekoaren balioak jaso dira, eguneko batez besteko balioetan oinarrituz.

4. taula. Arkitektura-eredu honen azpisailkapenaren eta erreferentzia klimatikoaren arabera lortutako Tenperatura Operatiboaren $\left[{ }^{\circ} \mathrm{C}\right]$ eta Hezetasun Erlatiboaren $[\%]$ datuak.

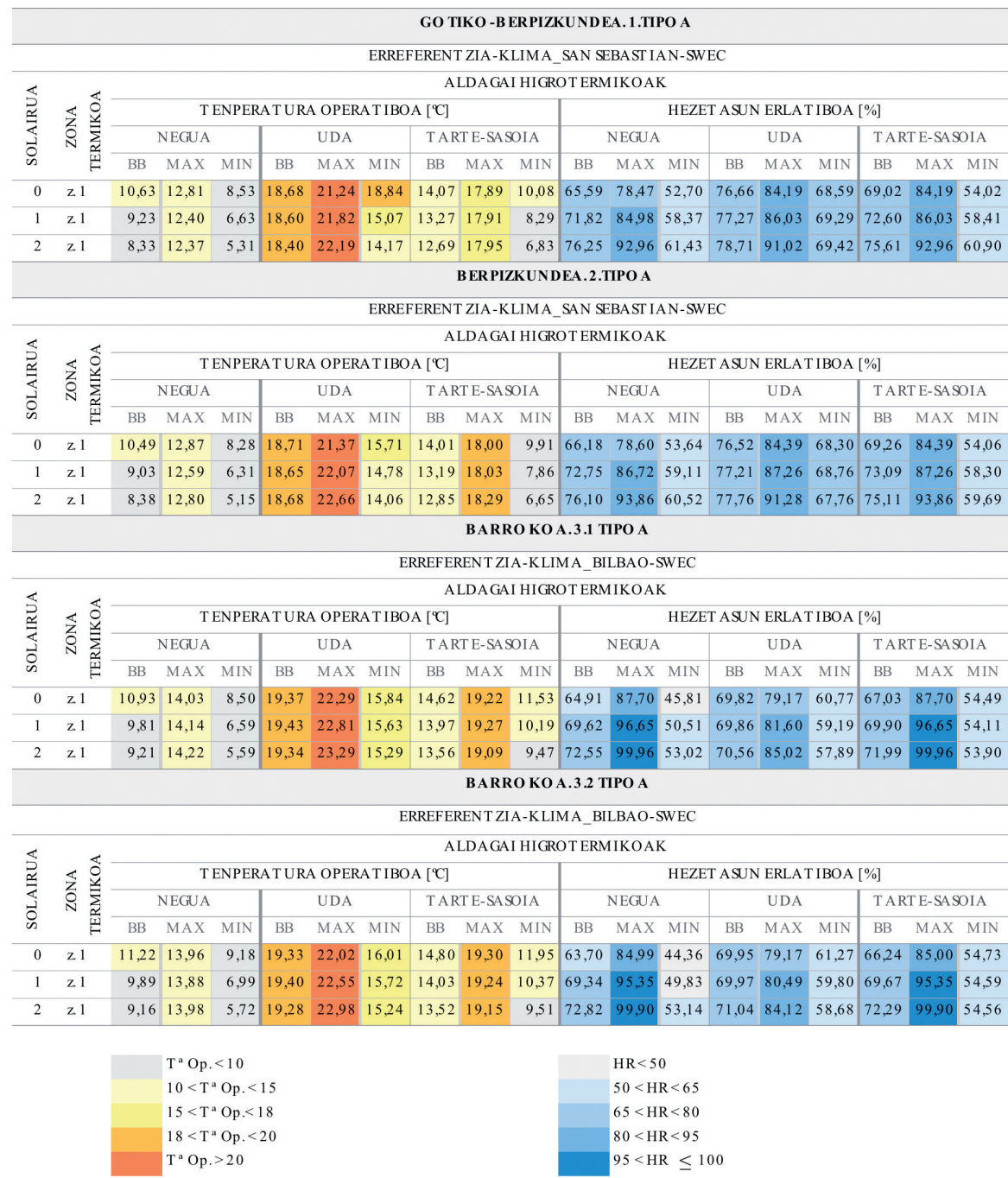


Horrela, beraz, haien kokapena, tokiko klima eta eraikuntza-ezaugarriak aintzat hartuta, portaera higrotermikoa aztertzea, ulertzea eta oinarrizko diagnosia lortzea posible izan da.

Oro har, esan liteke eredu guztien artean «behe-oineko 1 zona termikoan» gertatzen dela gorabehera termikorik apalena (batez beste $13,1{ }^{\circ} \mathrm{C}$ ), eta bigarren solairuko gune termiko berdinean, aldiz, gorabeherarik handiena (batez beste $17,34^{\circ} \mathrm{C}$ ). Halaber, aipatutako azken zona termiko horretan lortzen dira tenperatura operatiboaren baliorik baxuenak neguan (batez beste $5,44{ }^{\circ} \mathrm{C}$ ), bai eta beroenak ere udan (batez beste $22,78^{\circ} \mathrm{C}$ ). Irakurketa orokor horren ondorioz, beraz, portaera termiko bertsu baten adierazgarri, izan, badirela ondoriozta daiteke (4. irudia), nahiz eta eraikuntza-ezaugarri desberdinak dituzten azpiereduak izan eta datuen artean ere aldeak, egon, badauden.

\section{TENPERATURA OPERATIBOAREN BALIOAK $\left[{ }^{\circ} \mathrm{C}\right]$}

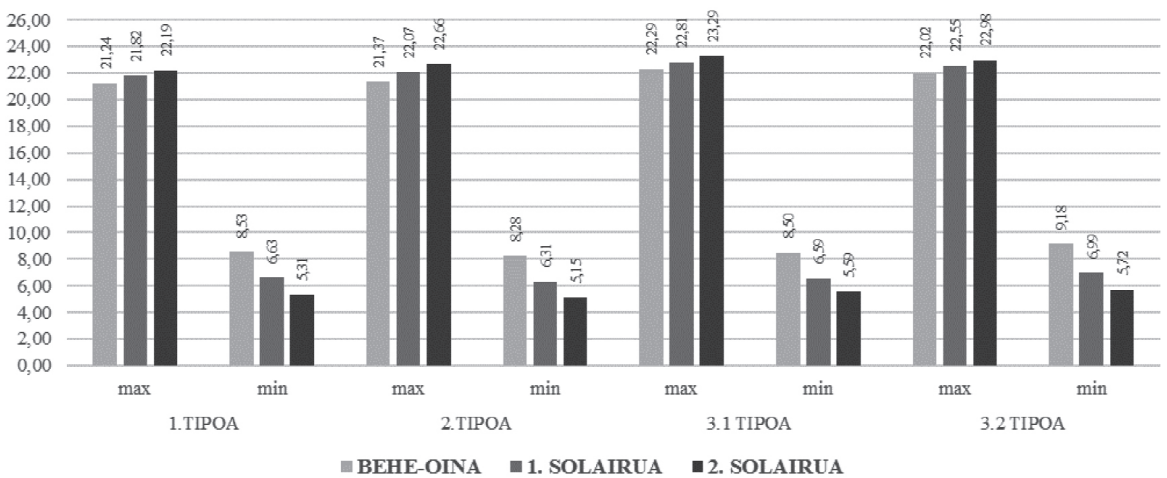

4. irudia. Tenperatura Operatiboaren balio maximo eta minimoen grafikoa. Balioak eraikin tipoaren eta solairuaren azpisailkapenaren arabera aurkezten dira.

Hala, eredurik zaharrenak eta berrienak alderatuz gero, hau da, eraikuntza-bilakaera kontuan izanez gero, azpieredu berrienak egonkorragoak eta epelagoak direla esan liteke, azken horietako tenperatura operatiboek egonkortasuna erdietsi baitute azterturiko hiru urteko aldietan.

Bestalde, barne-hezetasun erlatiboaren maila handia da urte osoan zehar, eraikuntza-sistemaren bilakaeraren ondorioz baino gehiago tokiko erreferentzia-klimaren eraginez. Eredu guztietan, uda da sasoirik egonkorrena, eta negua, aldiz, aldakorrena. Nahiz eta San Sebastian-SWEC klimapean simulatutako ereduen urteko hezetasun-maila handiagoa izan, lortutako balioak egonkorragoak dira, eta ez dira asetasun-puntura heltzen, Bilbao-SWEC klimaren arabera simulatutakoetan gertatzen den bezala. Portaera termikoarekin bat eginez, hezetasun-konforteko egoerarekin 
Matxalen Etxebarria Mallea, Lauren Etxepare Igiñiz,

Margarita de Luxán García de Diego

$(\% 20 \leq \mathrm{HR} \leq \% 80)$ lotutako balio erosoenak «behe-oineko 1 zona termikoan» gertatzen dira (solairuekin batera goratzen da hezetasuna).

\section{ONDORIOAK}

Artikulu honetan azaldutako metodologiaren eta emaitzen arabera, hau da, Tenperatura Operatiboaren balio gorenak (uda) eta baxuenak (negua) kronologikoki alderatzen badira, esan liteke eraikuntza-bilakaerak landaarkitekturaren eredu tradizional honen portaera higrotermikoan ezkutuko edo ezagutu gabeko eragin onuragarria izan duela. Izan ere, nahiz eta aztertutako portaera pasiboaren ondorioz lortutako datuen arteko desberdintasuna izugarrizkoa ez izan, argi ikusten da azpiereduetan kronologikoki aurrera egin ahala eraikinak epelagoak direla (5. taula, 4.-5. irudiak).

5. taula. «1 zona termikoko»Tenperatura Operatiboaren balio maximo eta minimoen batez besteko datuak eraikin tipoaren eta solairuaren arabera.

\begin{tabular}{l|l|ccc|cccc}
\hline \multicolumn{2}{c|}{} & \multicolumn{3}{c|}{$\begin{array}{c}\text { Maximoen } \\
\text { batezbestekoa }\left[{ }^{\circ} \mathbf{C}\right]\end{array}$} & \multicolumn{3}{c}{$\begin{array}{c}\text { Minimoen } \\
\text { batezbestekoa }\left[{ }^{\circ} \mathbf{C}\right]\end{array}$} \\
\cline { 3 - 9 } \multicolumn{2}{l|}{} & Behe-oina & $1 . a$ & $2 . a$ & Behe-oina & $1 . a$ & $2 . a$ \\
\hline Gotiko-berpizkundea & 1. tipoa & 21,24 & 21,82 & 22,19 & 8,53 & 6,63 & 5,31 \\
\hline Berpizkundea & 2. tipoa & 21,37 & 22,07 & 22,66 & 8,28 & 6,31 & 5,15 \\
\hline \multirow{2}{*}{ Barrokoa } & 3.1 tipoa & 22,29 & 22,81 & 23,29 & 8,50 & 6,59 & 5,59 \\
& 3.2 tipoa & 22,02 & 22,55 & 22,98 & 9,18 & 6,99 & 5,72 \\
\hline
\end{tabular}

UDA-SASOIKO HILABETE BATEKO TENPERATURAREN JOERA

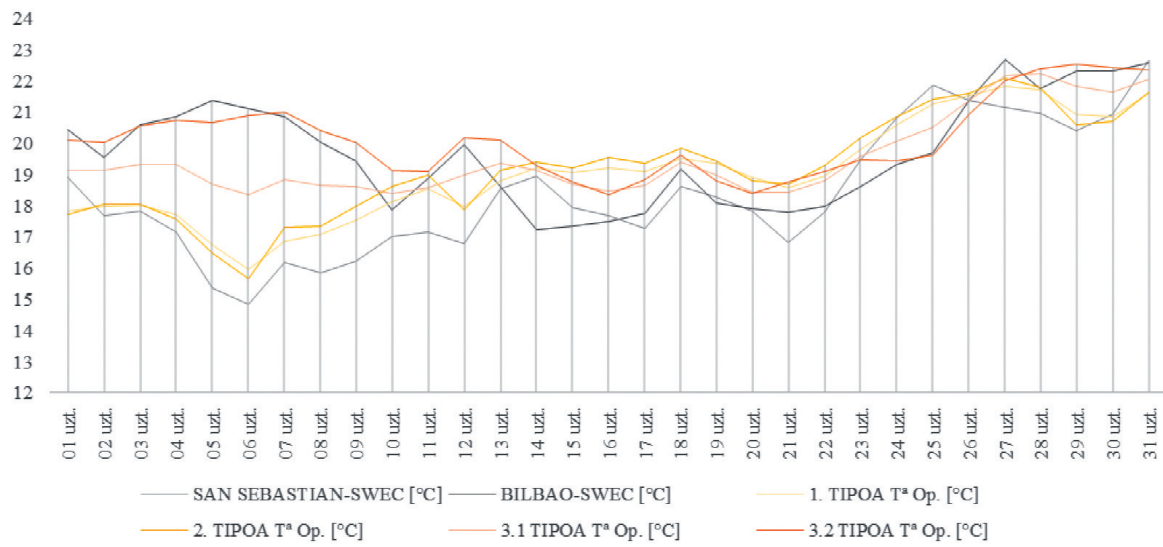

5. irudia. Tipo bakoitzeko «lehenengo solairuko 1 zona termikoko» uda-sasoiko hilabete bateko (uztaila) kanpo- eta barne-tenperaturaren joera. 
NEGU-SASOIKO HILABETE BATEKO TENPERATURAREN JOERA

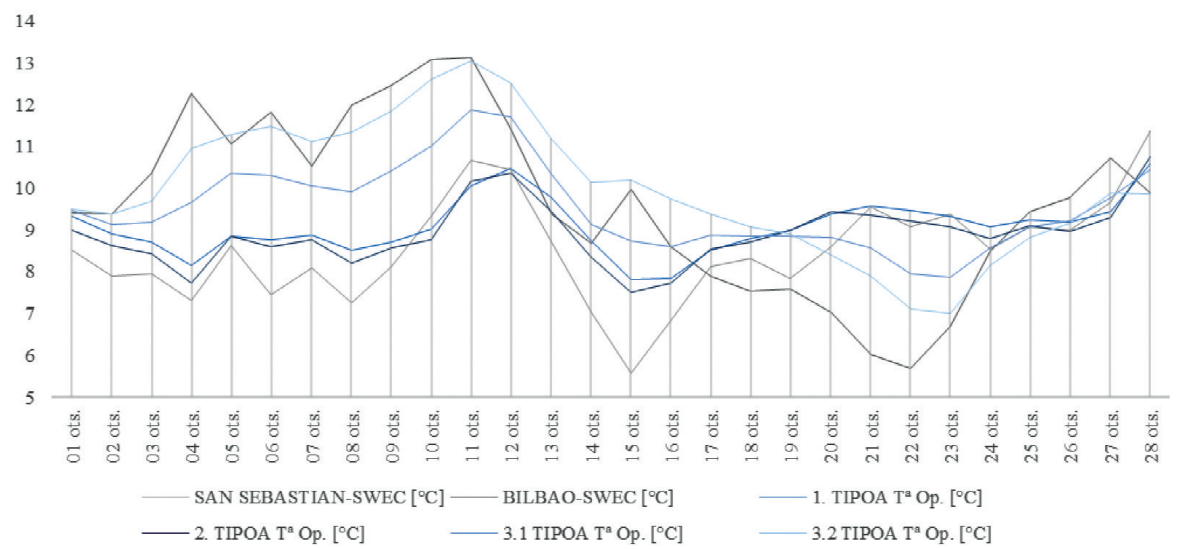

6. irudia. Tipo bakoitzeko «lehenengo solairuko 1 zona termikoko» negu-sasoiko hilabete bateko (otsaila) kanpo- eta barne-tenperaturen joera.

Bestalde, tokiko klima hezeak tarteko, barneko hezetasun erlatiboa altua da urte osoan zehar azpieredu guztietan, eta horrek eragin zuzena du barneko giza ongizate edo erosotasunean, halako balio altuen ondorioz sentsazio termikoa kaskartu egiten baita.

Hala ere, lortutako balio higrotermikoek kanpo-barru erlazioan garatutako oreka bat egon dela iradokitzen dute, erlazioaren eraginkortasuna arkitektura-, material- eta eraikuntza-ezaugarrien bilakaerarekin lotuz. Beraz, eraikin eredu tradizional honen barne-giroaren garrantzia eta portaera-eredua oinarrizko balioak dira, eta, hortaz, arkitektura-ondarearen ikuspegitik kontuan hartu beharrekoak, bai babeserako, bai eta esku-hartzeen neurria zehazteko ere [24-25].

Landutako metodologia eta lortutako datuak eremu geografiko zehatz batera mugatuta badaude ere, gertuko eremuetarako zein euskal lurralde osorako dira orientagarri eta baliagarriak, lekuan lekuko aldaerak badaudela jakinik betiere. Halaber, datu teorikoen doitasuna eta fidagarritasuna bermatzeko, datu errealetan oinarritutako lekuko neurketak egitea ezinbestekotzat jotzen da.

\section{ESKER ONAK}

Artikulu hau Lea ibarreko arkitektura-ondare tradizionala eta energiaizaera ikertzen dituen doktorego-tesiaren barruan kokatzen da, eta hura garatzeko Eusko Jaurlaritzako Hezkuntza, Hizkuntza Politika eta Kultura Sailak doktore ez diren ikertzaileak prestatzeko eskaintzen duen doktoratu 
Matxalen Etxebarria Mallea, Lauren Etxepare Igiñiz,

Margarita de Luxán García de Diego

aurreko programari esker jasotako laguntza baliatu da. Halaber, etxejabeek, Eusko Jaurlaritzako Ondare Zentroak eta Learri S.A.k emandako laguntza ere eskertu nahi dira.

\section{BIBLIOGRAFIA}

[1] JIMÉNEZ, M. eta GONÇALVES, L. 2015. «Bioclimatic analysis for a vernacular Guarani house». Vernacular Architecture. Towards a Sustainable Future. CRC Press, Taylor \& Francis Group, Balkema. 377-380.

[2] BODACH, S., LANG, W. eta HAMHABER, J. 2014. «Climate responsive building design strategies of vernacular architecture in Nepal». Energy and Buildings, 81, 227-242.

[3] TANG, L., NIKOLOPOULOU, M. eta ZHANG, N. 2014. «Bioclimatic design of historic villages in central-western regions of China». Energy and Buildings, 70, 271-278.

[4] DESOGUS, G., FELICE, L.G. eta SANNA, A. 2016. «Bioclimatic lessons from Mediterranean vernacular architecture: The Sardinian case study». Energy and Buildings, 129, 574-588.

[5] DE LUXÁN, M. et al. 2011. Habitar sostenible. Integración medioambiental en 15 casas de arquitectura popular española. Centro de Publicaciones Secretaría General Técnica, Ministerio de Fomento, Madrid.

[6] GIL CRESPO, I. J., BARBERO BARRERA, M. D. M., eta MALDONADO RAMOS, L. 2015. «Climatic analysis methodology of vernacular architecture». Vernacular Architecture. Towards a Sustainable Future. CRC, Taylor \& Francis Group, Balkema. 231-237.

[7] TZIKOPOULOS, M. F., KARATZA, M.C. eta PARAVANTIS, J. A. 2005. «Modeling energy efficiency of bioclimatic buildings». Energy and Buildings, 37, 529-544.

[8] MONTALBÁN POZAS, B. eta NEILA GONZÁLEZ, F.J. 2016. «Hygrothermal behaviour and thermal comfort of the vernacular housing in the Jerte Valley (Central System, Spain)». Energy and Buildings, 130, 219-227.

[9] MARTÍN, S., MAZARRÓN, F. R. eta CAÑAS, I. 2010. «Study of thermal environment inside rural houses of Navapalos (Spain): The advantages of reuse buildings of high thermal inertia». Construction and Building Materials, 24, 666-676.

[10] GAZTELU, U. 2012. «Baserrien analisi termikoa» Ardiri aldizkaria, 10, 34-35.

[11] DE YRIZAR, J. 1929. Las casas vascas: torres, palacios, caseríos, chalets, mobiliario. Librería Internacional, Donostia-San Sebastián.

[12] BAESCHLIN, A. 1930. La arquitectura del caserío vasco. Canosa, Barcelona.

[13] DE LA IGLESIA, A. 1978. El caserío, en el paisaje rural de Vizcaya. Caja de Ahorros Vizcaína, Bilbao. 
Euskal landa-arkitekturako eredu tradizionalaren eraikuntza-bilakaeraren eragina portaera higrotermiko pasiboan: Lea ibarreko kasu-azterketa

[14] BARRIO LOZA, J. A. et al. 1990. Bizkaia: Arqueología, Urbanismo y Arquitectura Histórica. Vol. 2: Markina-Ondarroa, Gernika-Bermeo, PlentziaMungia. Diputación Foral de Bizkaia, Bilbao.

[15] SANTANA, A. et al. 2001. Euskal Herriko Baserriaren Arkitektura. Vol. 1. Servicio Central de Publicaciones del Gobierno Vasco, Vitoria-Gasteiz.

[16] Código Técnico de la Edificación, Documento Básico de Ahorro de Energía, Apéndice B-Zonas climáticas. Junio 2017. (Azken kontsulta data 2017-06) https://www.codigotecnico.org/images/stories/pdf/ahorroEnergia/DcmHE. pdf

[17] Spanish Weather for Energy Calculations (SWEC) for Energy Plus. (Azken kontsulta data 2017-06) https://energyplus.net/weather-region/europe_wmo_ region_6/ESP

[18] Agencia Estatal de Meteorología (AEMET), Atlas Climático Ibérico-Iberian Climate Atlas. (Azken kontsulta data 2018-04) http://www.aemet.es/ documentos/es/conocermas/publicaciones/Atlas-climatologico/Atlas.pdf

[19] AGUIAR, R. 1996-1997. INETI (Lisboa, Portugal), Research contract with foundation: Climatic Synthetic time Series for the Mediterranean Belt (CLIMED), Contract no JOR3-CT96-0042, DG XII.

[20] SUSPERREGI, J., TELLERIA, I., URTEAGA, M. eta JANSMA, E. 2017. «The Basque farmhouses of Zelaa and Maiz Goena: new dendrochronologybased findings about the evolution of the built heritage in the northern Iberian peninsula». Journal of Archaeological Science: Reports, 11, 695-708.

[21] ETXEBARRIA MALLEA, M. 2017. «La influencia de las técnicas constructivas y compositivas del barroco en la arquitectura tradicional del País Vasco. Caso de estudio del Valle del Lea». Actas del X Congreso InterNacional y II HispanoAmericano de Historia de la Construcción. Donostia-San Sebastián. 1, 501-511.

[22] Código Técnico de la Edificación. Catálogo de Elementos Constructivos. Marzo 2010. (Azken kontsulta data 2017-06) https://www.codigotecnico. org/images/stories/pdf/aplicaciones/nCatalog_infoEConstr/CAT-EC-v06.3_ marzo_10.pdf

[23] GAZTELU, U. 2016. «Hacia una adaptación sostenible del caserío vasco. Towards a sustainable adaptation of Basque farmhouses». Doktorego Tesia, 457.

[24] CAÑAS, I. eta MARTÍN, S. 2004. «Recovery of Spanish vernacular construction as a model of bioclimatic architecture». Building and Environment, 39, 1477-1495.

[25] GAZTELU, U., DE LA FUENTE, A., AZKARATE, A. eta RODRIGUEZ, J. 2013. "The protection of the baserri as an energy efficient building: the optimized insulation strategy». Proceedings of the $13^{\text {th }}$ International Conference STREMAH, New Forest. 